\title{
Functional and structural alterations in the endoplasmic reticulum and mitochondria during apoptosis triggered by $\mathrm{C}_{2}$-ceramide and CD95/AP0-1/FAS receptor stimulation
}

\author{
Davide Ferrari ${ }^{\mathrm{a}, 1}$, Paolo Pinton ${ }^{\mathrm{a}, 1}$, Michelangelo Campanella ${ }^{\mathrm{c}, \mathrm{d}, *, 1}$, Maria Giulia Callegari ${ }^{\mathrm{a}}$, Cinzia Pizzirani ${ }^{\mathrm{a}}$, \\ Alessandro Rimessi ${ }^{a}$, Francesco Di Virgilio ${ }^{a}$, Tullio Pozzan ${ }^{b}$, Rosario Rizzuto ${ }^{\mathrm{b}, *}$

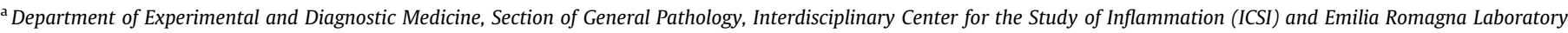 \\ BioPharmaNet, University of Ferrara, Ferrara, Italy \\ ${ }^{\mathrm{b}}$ Department of Biomedical Sciences and CNR Center for the Study of Biomembranes, University of Padua, Padova, Italy \\ ${ }^{\mathrm{c}}$ Department of Veterinary Basic Science, Royal Veterinary College, Royal College Street, University of London, NW1 0TU, United Kingdom \\ ${ }^{\mathrm{d}}$ Consortium for Mitochondrial Research, University College London, WC1E 6BT, United Kingdom
}

\section{A R T I C L E I N F O}

\section{Article history:}

Received 12 November 2009

Available online 24 November 2009

\section{Keywords:}

CD95

Ceramide

Apoptosis

Mitochondria

Endoplasmic reticulum

$\mathrm{Ca}^{2+}$

\begin{abstract}
A B S T R A C T
$\mathrm{C}_{2}$-ceramide $\left(\mathrm{C}_{2}\right.$-cer) and binding of the CD95/APO-1/FAS (aCD95) receptor are acknowledged inducers of apoptosis. In spite of that, their effects on the endoplasmic reticulum (ER) and mitochondria during early phases of apoptotic onset are poorly characterized. Here, by employing various approaches, we followed structural and functional modifications of these organelles at the beginning of cellular demise.

In detail, we observed that $\mathrm{C}_{2}$-cer, but not CD95 activation, markedly modifies the morphology of the ER and promotes $\mathrm{Ca}^{2+}$ release. Accordingly, mitochondria of $\mathrm{C}_{2}$-cer-treated, but not of $\mathrm{CD} 95$-stimulated, cells are fragmented, show reduced $\mathrm{Ca}^{2+}$ uptake, and collapsed membrane potential $\left(\Delta \Psi_{\mathrm{m}}\right)$. Most notably, $C_{2}$-cer-mediated morphological aberrations of the ER are prevented neither by the pan-caspase inhibitor Z-VADfmk nor by the cell cytoskeleton dissembler cytochalasin-D, while on the contrary they are reduced by incubation in the presence of the intracellular $\mathrm{Ca}^{2+}$ chelator 1,2-bis $(O$-aminophenoxy)ethane- $N, N, N^{\prime}, N^{\prime}$-tetraacetic acid (BAPTA). We conclude that initiation of apoptosis via the intrinsic (i.e. $C_{2^{-}}$ cer mediated) pathway causes an early structural and functional alteration of both ER and mitochondria, thus underlying a final "non return" point in the apoptotic pathway.
\end{abstract}

(c) 2009 Elsevier Inc. All rights reserved.

\section{Introduction}

Apoptosis is a form of cell death that can be pre-programmed, such as during development [1], or stimulated by a variety of stress or signals [2]. It is characterized by morphologic and biochemical changes orchestrated by a family of cysteine proteases known as caspases [3]. Caspase activation executes the apoptosis process by cleaving various intracellular substrates, eventually leading to plasma membrane blebbing, genomic DNA fragmentation, and exposure on the cell surface of phagocytosis signalling molecules [4]. Apoptosis can be triggered by the engagement of plasma membrane receptors belonging to a subgroup of the TNF-receptor superfamily known as death receptors [5] among which CD95/ APO-1/Fas is probably the best known [6]. Interaction of CD95 with its agonistic antibody (aCD95) induces receptor oligomerisation,

\footnotetext{
* Corresponding authors. Fax: +44 2074685204 (M. Campanella).

E-mail addresses: mcampanella@rvc.ac.uk (M. Campanella), r.rizzuto@unipd.it (R. Rizzuto).

1 These authors equally contributed to this work.
}

followed by the recruitment, through homophilic interactions, of adaptor proteins to the death domain and activation in a transcription-independent manner of the death-inducing caspase cascade, which causes cytochrome $c$ release, and further activation of caspases and DNAses. The CD95 pathway plays an important role in regulating the immune system [7], and has been implicated in cancer, human immunodeficiency, virus infection, stress, ageing and even drug abuse [8].

Ceramide is a lipid second messenger generated by de novo synthesis or by the hydrolysis of sphingomyelin [9] that plays a role in several biological phenomena such as differentiation, growth suppression, senescence [10], cell stress [11] and apoptosis [12].

Changes in cytosolic $\mathrm{Ca}^{2+}$ concentration $\left(\left[\mathrm{Ca}^{2+}\right]_{c}\right)$ trigger key cellular functions, ranging from muscle contraction to secretion of neurotransmitters and modulation of metabolism [13]. $\mathrm{Ca}^{2+}$ also plays a major role in the regulation of mitochondrial physiology and cell death $[14,15]$. Notably, although the central role of mitochondria in programmed cell death is widely recognised [16], a major role of the ER in apoptosis emerged later and particularly in decoding apoptotic signals involving alterations in cellular 
$\mathrm{Ca}^{2+}$ homeostasis [17]. The $\mathrm{Ca}^{2+}$ storage capacity of the ER is therefore the target of pharmacological agents that facilitate apoptotic cell death [18].

A major involvement of the ER has been demonstrated in NOinduced apoptosis [19] and ER stress has been shown to induce procaspase and calpain activation with the subsequent degradation of different substrates both in the ER and in the cytosol [20]. Disturbances in cellular redox regulation, glucose deprivation and viral infections are all cellular conditions leading to ER stress. This may be associated with an accumulation of unfolded proteins to trigger the so called unfolded protein response (UPR) [21]: an evolutionarily conserved physiological response that may lead to cell demise via apoptosis or autophagy. In this process, $\mathrm{Ca}^{2+}$ deregulation within the ER may be key [22].

Aim of this work was to investigate by a combination of morphological and functional approaches the involvement of the ER and mitochondria in apoptosis triggered by $\mathrm{C}_{2}$-cer and aCD95, two prototypic examples of initiation of apoptosis via the intrinsic and extrinsic pathway, respectively. Our data suggest that these two classical apoptotic stimuli have dramatically different impact on the morphology and physiology of the ER and mitochondria.

\section{Materials and methods}

Cells, solutions, and reagents. HeLa cells were grown in Dulbecco's modified Eagle's medium (DMEM) (Euroclone, I), supplemented with $10 \%$ FCS (Life Technologies, I), in $75 \mathrm{~cm}^{2}$ flasks (Falcon, Franklin Lakes, USA). Krebs-Ringer modified Buffer (KRB) contained: $125 \mathrm{mM} \mathrm{NaCl}, 5 \mathrm{mM} \mathrm{KCl}, 1 \mathrm{mM} \mathrm{MgSO}_{4}, 1 \mathrm{mM} \mathrm{Na}_{2} \mathrm{HPO}_{4}$, $5.5 \mathrm{mM}$ glucose, $1 \mathrm{mM} \mathrm{CaCl}, 20 \mathrm{mM} \mathrm{NaHCO}$, $2 \mathrm{mM}$ L-glutamine and $20 \mathrm{mM}$ Hepes ( $\mathrm{pH}$ 7.4). For permeabilized cells, an intracellular buffer (IB) was employed: $140 \mathrm{mM} \mathrm{KCl}, 10 \mathrm{mM} \mathrm{NaCl}, 1 \mathrm{mM} \mathrm{K}_{3} \mathrm{PO}_{4}$, $5.5 \mathrm{mM}$ glucose, $2 \mathrm{mM} \mathrm{MgSO}_{4}, 1 \mathrm{mM}$ ATP, $2 \mathrm{mM}$ sodium succinate, $20 \mathrm{mM}$ Hepes (pH 7.05 at $\left.37^{\circ} \mathrm{C}\right)$.

Ionomycin, histamine, digitonin, $N$-acetyl-D-sphingosine $\left(\mathrm{C}_{2}\right.$ ceramide) and D-erythro- $N$-acetylsphinganine $\left(\mathrm{C}_{2}\right.$-dihydroceramide), 1,2-bis(2-aminophenoxy)ethane- $N, N, N^{\prime}, N^{\prime}$-tetraacetic acid tetrakis(acetoxymethyl ester) (BAPTA), were purchased from Sigma-Aldrich (I), coelenterazine and Fura-2/AM from Molecular Probes (NL).

Transfection. Transfection was done with the $\mathrm{Ca}^{2+}$-phosphate technique [23]. For the aequorin measurements, cells seeded onto $13 \mathrm{~mm}$ coverslips (BDH, I) were transfected with $4 \mu \mathrm{g}$ mtAEQ; for GFP experiments, cells were seeded onto $24 \mathrm{~mm}$ coverslips and transfected with $8 \mu \mathrm{g}$ mtGFP or erGFP.

Aequorin measurements. Thirty-six hours after transfection the cells were incubated with $5 \mu \mathrm{M}$ coelenterazine for 1-2 h in DMEM supplemented with $1 \%$ FCS and then transferred to the perfusion chamber. All aequorin measurements were carried out in KRB, supplemented with $1 \mathrm{mM} \mathrm{Ca}^{2+}$. Agonists and other drugs were added to the same medium. Experiments were terminated by lysing cells with $100 \mu \mathrm{M}$ digitonin in a hypotonic $\mathrm{Ca}^{2+}$-rich solution $(10 \mathrm{mM}$ $\mathrm{CaCl}_{2}$ in $\mathrm{H}_{2} \mathrm{O}$ ). The light signal was collected and calibrated into $\left[\mathrm{Ca}^{2+}\right]$ values [23].

Microscopic analyses. The coverslips with the cells were placed in a thermostatted Leyden chamber, (model TC-202A, Medical Systems Corp., NY, USA) on the stage of an inverted Nikon Eclipse TE300 microscope (Nikon, Tokyo, JP) equipped with epifluorescence and a piezoelectric motorization of the objective (Physik Instrumente, $\mathrm{GmbH} \& \mathrm{Co}$., DE). The images were captured by a back-illuminated CCD camera (Pricenton Instruments, AZ, USA) using the Metamorph software (Universal Imaging Corporation, PA, USA). In the computationally deblurred images of Fig. 3 a stack of images through the $z$ plane was acquired and processed using the EPR software developed by the Biomedical Imaging group (Worcester, MA, USA).
$\left[\mathrm{Ca}^{2+}\right]_{c}$ measurements. Changes in the $\left[\mathrm{Ca}^{2+}\right]_{c}$ were measured with the fluorescent indicator Fura-2/AM using an LS50 Perkin Elmer fluorometer (Perkin Elmer Ltd., Beaconsfield, UK). The cells $\left(1 \times 10^{7} / \mathrm{ml}\right)$ were suspended in $1 \mathrm{mM} \mathrm{Ca}^{2+} / \mathrm{KRB}$ containing $2 \mu \mathrm{M}$ Fura-2/AM and $250 \mu \mathrm{M}$ sulfinpyrazone (Sigma) at $37^{\circ} \mathrm{C}$ for $15 \mathrm{~min}$. After washing changes in $\left[\mathrm{Ca}^{2+}\right]_{\mathrm{c}}$ were determined in a thermostated, magnetically stirred cuvette, with the 340/380 excitation ratio at an emission wavelength of $505 \mathrm{~nm}$.

Imaging mitochondrial membrane potential $\left(\Delta \Psi_{\mathrm{m}}\right)$. Tetramethyl rhodamine methyl ester (TMRM) (Invitrogen) was used in "redistribution mode" and was present continuously at concentration of $50 \mathrm{nM}$ distributing between cellular compartments in response to different potentials. TMRM fluorescence was quantified by removing all background signals by 'thresholding' and measuring the mean fluorescence intensity in the pixels containing mitochondria.

\section{Results}

CD95 activation and $C_{2}$-ceramide differently affect ER morphology and intracellular $\mathrm{Ca}^{2+}$ homeostasis

HeLa cells treated with $\mathrm{C}_{2}$-cer or aCD95 undergo apoptotic cell death with similar efficiency and a comparable time course [24]. We confirmed this by counting the percentage of apoptotic cells after $6 \mathrm{~h}$ incubation with either $1 \mu \mathrm{g} / \mathrm{ml}$ aCD95 or $20 \mu \mathrm{M} \mathrm{C} \mathrm{C}_{2}$-cer. Specifically, cells were seeded onto coverslips and grown in DMEM. When $70 \%$ confluence was reached, the incubation medium was switched to KRB modified buffer supplemented with either aCD95 or $\mathrm{C}_{2}$-cer. With both stimulants, $6 \mathrm{~h}$ after the challenge approximately $90 \%$ of the cells underwent apoptosis (data not shown) together with typical shrinkage and plasma membrane blebbing (Fig. 1A, B). In parallel, we dynamically followed changes in ER morphology. For this purpose, HeLa cells were transiently transfected with an ER-targeted GFP construct (erGFP) and positive cells were analysed at different time points with a high-resolution digital imaging system [25]. The experimental protocol itself did not affect ER morphology, as in the absence of the stimulants no changes in morphology were detected during a $6 \mathrm{~h}$ incubation in the microscopy chamber under repeated (12) short (1 s) light pulses (Supplementary Fig. 1A). Notably, aCD95 treated cells did not show appreciable modifications of the overall ER structure even after a $5 \mathrm{~h}$ treatment (length of time coinciding with caspase activation), nor the challenge caused any detectable increase in $\left[\mathrm{Ca}^{2+}\right]_{\mathrm{i}}$ (Fig. 1C, Ci).

In striking contrast, $\mathrm{C}_{2}$-cer dramatically affected both ER morphology and $\left[\mathrm{Ca}^{2+}\right]_{i}$ homeostasis. As shown in Fig. $1 \mathrm{D} \mathrm{C} \mathrm{C}_{2}$-cer caused detectable modifications of ER morphology as early as 10-20 min after its addition, while after $3 \mathrm{~h}$ the fine ER network was almost completely replaced by large round aggregates (Fig. 1D, see also Supplementary Fig. 1B). At variance with aCD95, $\mathrm{C}_{2}$-cer addition promoted a clear $\left[\mathrm{Ca}^{2+}\right]_{\mathrm{i}}$ rise consistent with a release of $\mathrm{Ca}^{2+}$ from the ER [26] (Fig. 1Di). In agreement with this interpretation, the subsequent addition of ionomycin (iono) did not cause a further $\left[\mathrm{Ca}^{2+}\right]_{\mathrm{i}}$ increase.

\section{$\left[\mathrm{Ca}^{2+}\right]_{i}$ buffering attenuates ER changes}

We then explored whether the morphological modifications of the ER were a direct consequence of $\mathrm{C}_{2}$-cer or a downstream effect due to caspase activation, and whether they were specific for the pro-apoptotic moiety of the lipid. For this purpose, HeLa cells expressing erGFP were pre-treated with the broad-spectrum caspase inhibitor Z-VADfmk $(100 \mu \mathrm{M})$ before incubation with $\mathrm{C}_{2}$-cer (Fig. 2C) and compared to cells treated with either $\mathrm{C}_{2}$-cer alone (Fig. 2A), or its inactive form, di- $\mathrm{C}_{2}$-cer $(20 \mu \mathrm{M})$ (Fig. 2B). As shown in Fig. 2A, Z-VADfmk $(100 \mu \mathrm{M})$ does not inhibit $C_{2}$-cer-induced 
A

\section{anti-CD95}

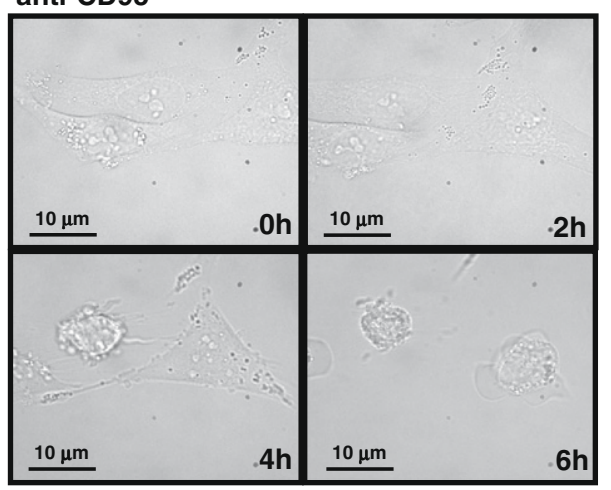

\section{C}

\section{anti-CD95}
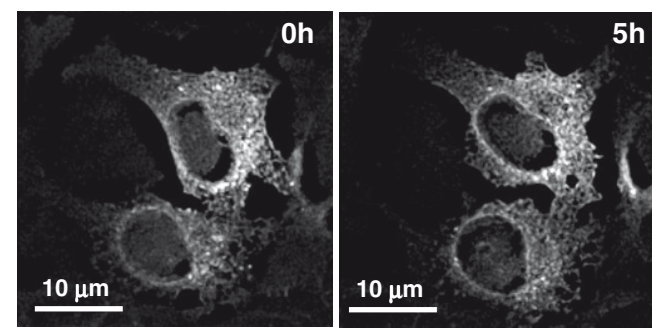

D
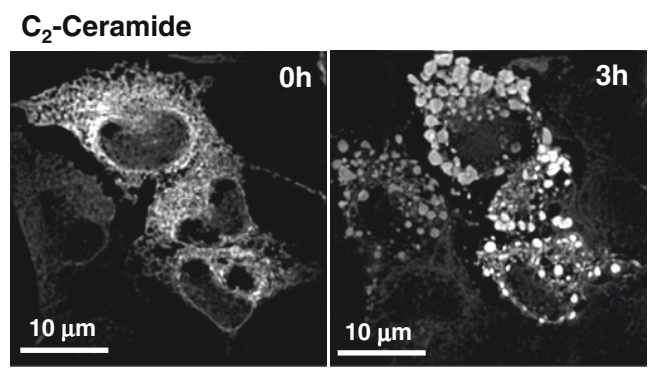

B

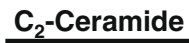

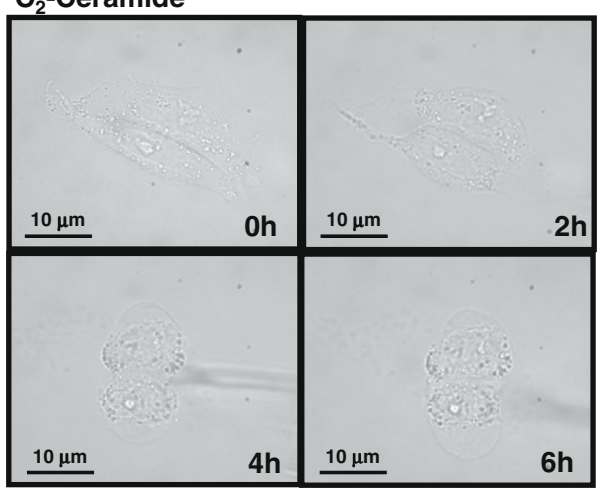

$\mathbf{C i}$

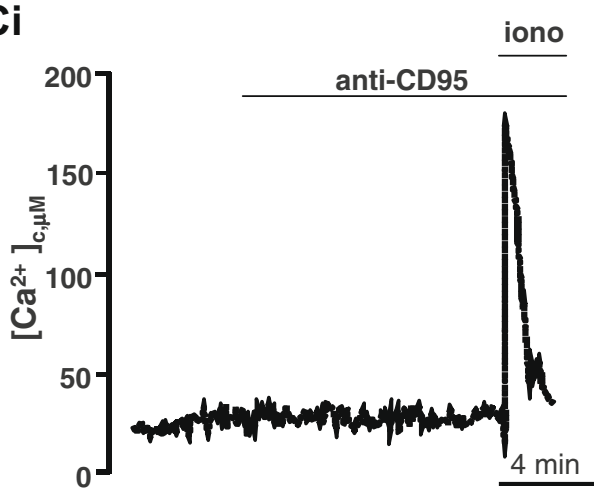

$\mathrm{Di}$

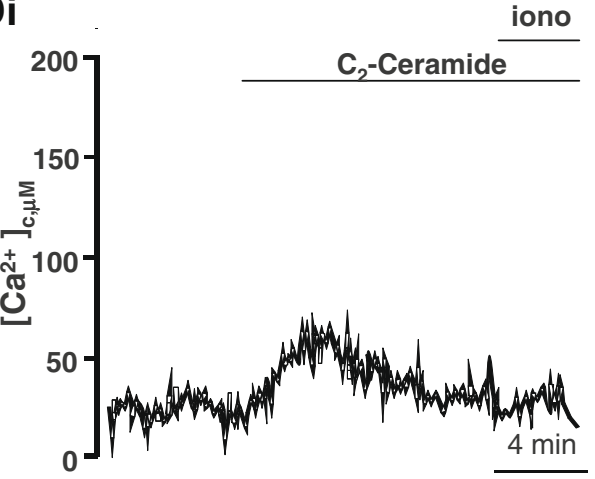

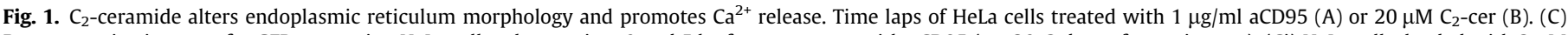

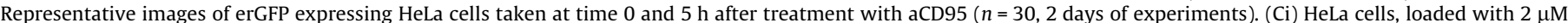

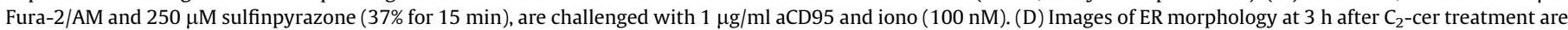
presented ( $n=20,3$ days of experiments) and in Di the evoked changes in $\left[\mathrm{Ca}^{2+}\right]_{\mathrm{c}}$ reported.

modifications and di- $\mathrm{C}_{2}$-cer has no effect on ER morphology. This suggested that ER disassembly is not a downstream effect in the apoptotic process but rather an early, specific event occurring upstream of caspase activation.

We then searched for potential effectors mechanisms. To test whether the cytoskeleton was targeted by $\mathrm{C}_{2}$-cer, erGFP-expressing HeLa cells were pre-treated with $20 \mu \mathrm{M}$ cytochalasin-D, an inhibitor of actin assembly. Fig. 2D shows that cytochalasin does not prevent the ER structural aberrations caused by $\mathrm{C}_{2}$-cer. We then investigated whether $\mathrm{Ca}^{2+}$ itself is responsible for ER changes. Firstly, we discharged ER $\mathrm{Ca}^{2+}$ by incubating HeLa cells in KRB medium supplemented with $100 \mathrm{nM}$ iono and $0.5 \mathrm{mM}$ EGTA. Notably, depletion of ER $\mathrm{Ca}^{2+}$ stores by this procedure reduced $\mathrm{C}_{2}$-certriggered ER alterations, albeit not completely (Fig. 2E). While this experiment calls for a primary role of $\mathrm{ER} \mathrm{Ca}^{2+}$, we further verified if also $\mathrm{Ca}^{2+}$ release into the cytosol may play a facilitator role for the morphological changes. We previously showed that the intracellular $\mathrm{Ca}^{2+}$ chelator BAPTA reduces the apoptotic efficacy of $\mathrm{C}_{2}$-cer, very likely by preserving mitochondrial integrity [16]. Here, we recorded that BAPTA loading [27] markedly reduced the ER modifications (Fig. 2F) thus suggesting a $\left[\mathrm{Ca}^{2+}\right]_{i}$ dependent step in the mechanism of action of $\mathrm{C}_{2}$-cer.

Mitochondrial $\mathrm{Ca}^{2+}$ and $\Delta \Psi_{m}$ are altered in $\mathrm{C}_{2}$-ceramide treated cells

After assessing the modifications occurring in the ER, we tested the effects of the $C_{2}$-cer and aCD95 on mitochondrial morphology and physiology. HeLa cells were transfected with a mitochondrially targeted GFP (mtGFP) and the organelle structure evaluated [25]. In control cells, mitochondria appeared tubular and interconnected in 

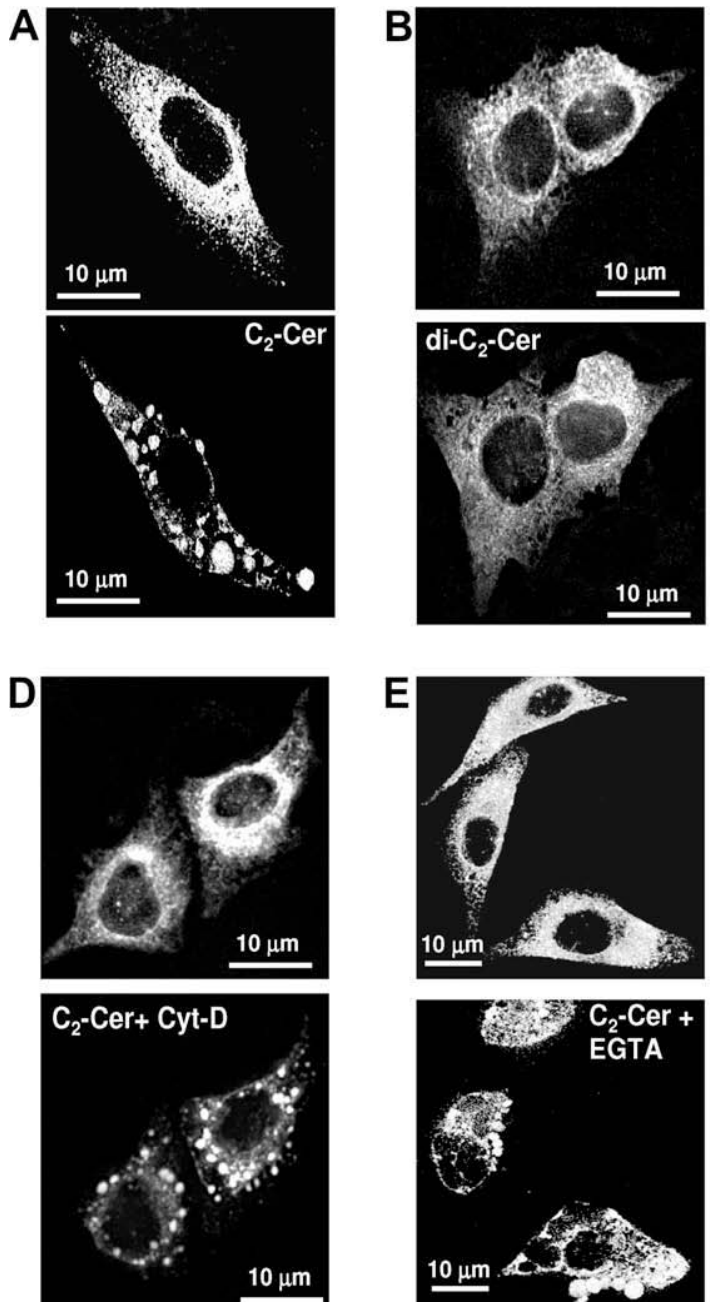

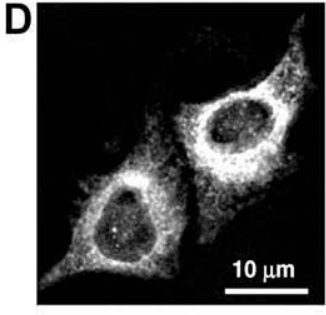

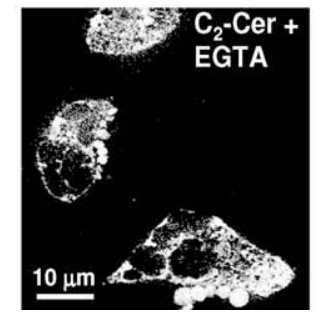
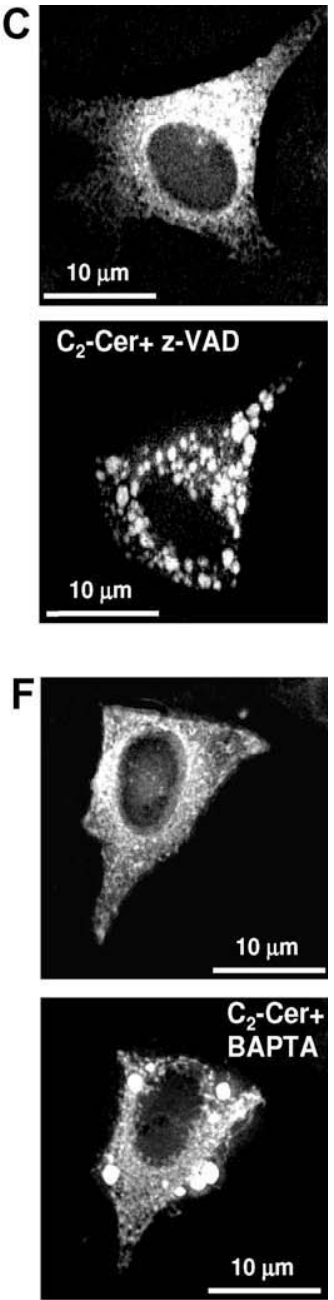

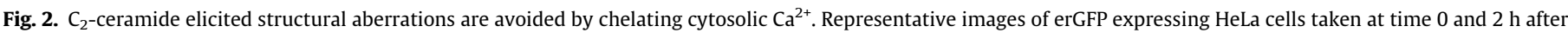

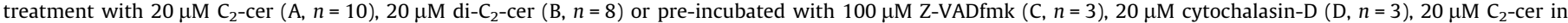
$0.5 \mathrm{mM}$ EGTA $\mathrm{Ca}^{2+}$-free medium $(\mathrm{E}, n=15)$ or $5 \mu \mathrm{M}$ BAPTA for $30 \mathrm{~min}$ at $37^{\circ} \mathrm{C}(\mathrm{F}, n=4)$.

a complex network that undergoes only marginal and localised morphological modifications even after 1 h incubation in the microscopy chamber (Fig. 3A). No changes were appreciable in cells stimulated with aCD95 antibodies (Fig. 3Ai), whilst mitochondrial morphology changed dramatically in $\mathrm{C}_{2}$-cer stimulated cells [27]. As soon as 30 min after $\mathrm{C}_{2}$-cer addition, the mitochondrial network begun to break-down, and after $1 \mathrm{~h}$ most of the mitochondria were rounded, shrunken and fragmented (Fig. 3Aii). We then investigated whether challenge with either $\mathrm{C}_{2}$-cer or aCD95 affects mitochondrial $\mathrm{Ca}^{2+}$ homeostasis. To this aim, by using a chimeric aequorin targeted to the mitochondrial matrix ( $\mathrm{mtAEQ}$ ), we monitored changes in mitochondrial $\left[\mathrm{Ca}^{2+}\right]\left(\left[\mathrm{Ca}^{2+}\right]_{\mathrm{m}}\right)$ elicited by an $\mathrm{IP}_{3}$-producing stimulus: histamine. Fig. 3B shows that in control cells histamine rapidly and transiently increases $\left[\mathrm{Ca}^{2+}\right]_{\mathrm{m}}$ reaching maximum values $\left(80 \pm 19.4 \mu \mathrm{M} \mathrm{Ca}^{2+}\right)$ similar to those detected in cells stimulated with aCD95 antibodies ( $87.4 \pm 29 \mu \mathrm{M} \mathrm{Ca}^{2+}$ ) (Fig. 3Bi). Thus, CD95 stimulation did not induce any change in the mitochondrial $\mathrm{Ca}^{2+}$ uptake capacity. Although the kinetics of the $\mathrm{Ca}^{2+}$ transients in $\mathrm{C}_{2}$-cer-stimulated cells were similar to those of control and aCD95-treated cells, $\mathrm{Ca}^{2+}$ increases were strongly reduced $\left(49.7 \pm 4.3 \mu \mathrm{M} \mathrm{Ca}^{2+}\right)$. This result was not surprising, considering the substantial $\mathrm{Ca}^{2+}$ depletion of the ER and the major morphological alterations of the mitochondria caused by $\mathrm{C}_{2}$-cer. We investigated however whether the intrinsic mitochondrial $\mathrm{Ca}^{2+}$ uptake capacity were reduced, e.g. due to a reduction of the electrochemical proton gradient. HeLa cells expressing mtAEQmut were perfused with a saline solution mimicking the ionic composition of the intracellular milieu (IB). The plasma membrane was then permeabilized by perfusing the cells for $1 \mathrm{~min}$ with IB/EGTA supplemented with $100 \mu \mathrm{M}$ digitonin. After a 2 min wash with IB/EGTA, $\mathrm{Ca}^{2+}$ accumulation into mitochondria was initiated by switching the perfusion medium to IB solution containing a free $\left[\mathrm{Ca}^{2+}\right]$ of $1 \mu \mathrm{M}$. The rate and amplitude of mitochondrial $\mathrm{Ca}^{2+}$ accumulation was almost identical in control and aCD95 treated cells $\left(12.2 \pm 5.2 \mu \mathrm{M} \mathrm{Ca}^{2+} / \mathrm{s}\right.$ vs $11.7 \pm 3.5 \mu \mathrm{M} \mathrm{Ca}^{2+} / \mathrm{s}$, respectively) while $\mathrm{C}_{2}$-cer-treated cells $\mathrm{Ca}^{2+}$ accumulation was significantly slower $\left(6.6 \pm 3.5 \mu \mathrm{M} \mathrm{Ca}^{2+} / \mathrm{s},{ }^{*} p<0.05\right)$ (Fig. 3C). In addition, we verified whether this was consistent with modifications in the mitochondrial membrane potential $\left(\Delta \Psi_{\mathrm{m}}\right)$ which provides the driving force for organelle $\mathrm{Ca}^{2+}$ uptake. HeLa cells were incubated with TMRM [28], at $50 \mathrm{nM}$ for $30 \mathrm{~min}$ and placed on the stage of a confocal microscope and challenged with the lipid solvent DMSO for controls, or with the $1 \mu \mathrm{g} / \mathrm{ml} \mathrm{aCD95}$ or $20 \mu \mathrm{M} \mathrm{C}_{2}$-cer. Images were acquired every $10 \mathrm{~min}$. Fluorescence emission recorded in each experimental condition $1 \mathrm{~h}$ after the addition of the agonist, normalized to control emission at time 0 , is shown in Fig. 3D (Time 0 , Control:1; aCD95:1.029 \pm 0.037; $C_{2}$-Cer:1.0056 \pm 0.03; Time $1 \mathrm{~h}$, Control:0.98 $\pm 0.072 n=84 ;$ aCD95: $1.091 \pm 0.03, n=114 ; C_{2}$-Cer:0.638 \pm 0.039 $\left.n=120,{ }^{*} p<0.05\right)$. Overall, the data show a decrease in $\Delta \Psi_{\mathrm{m}}$ that well matches the reduction in mitochondrial $\mathrm{Ca}^{2+}$ uptake observed both in intact and permeabilized cells [16]. 
A

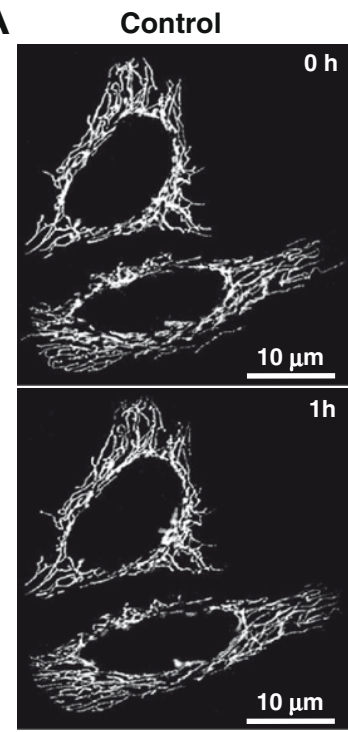

Ai
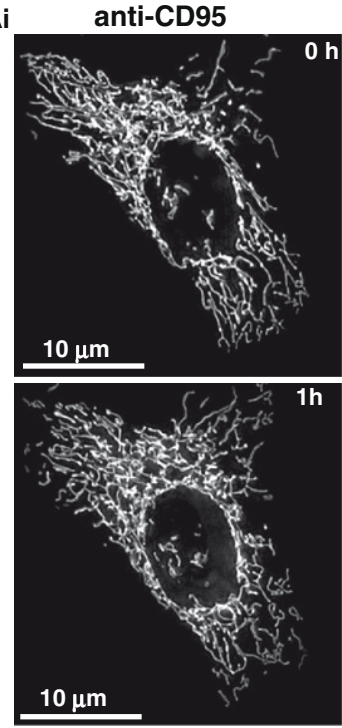

Aii

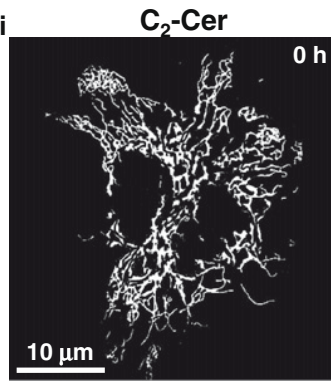

\section{(1)}

B

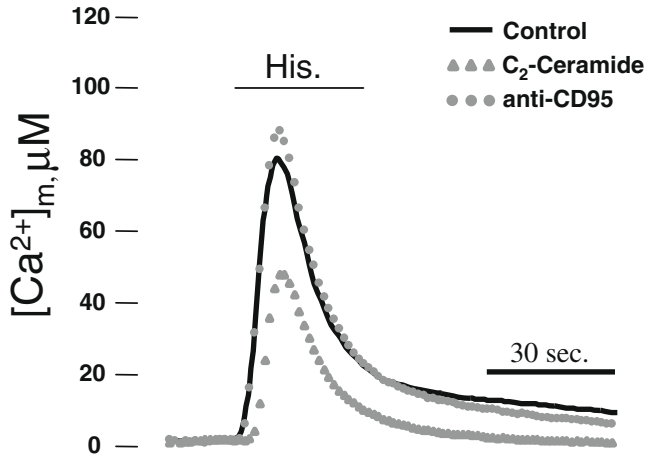

Bi

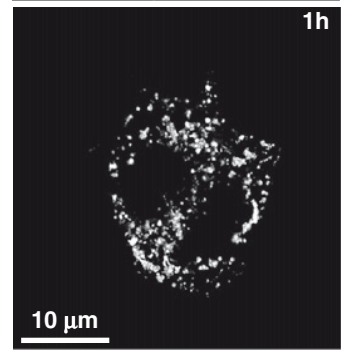

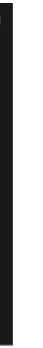

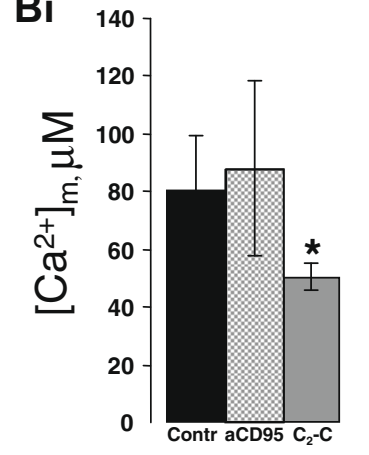

C
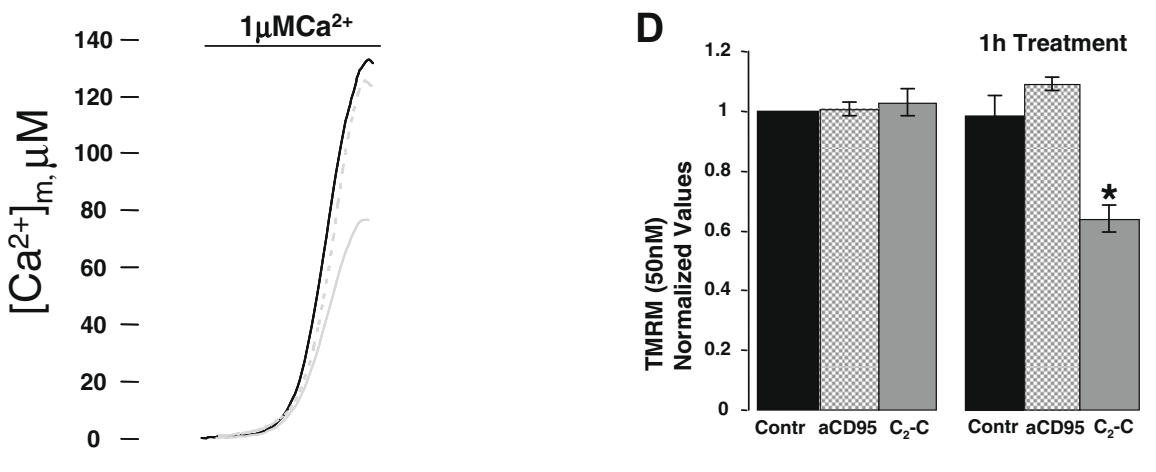

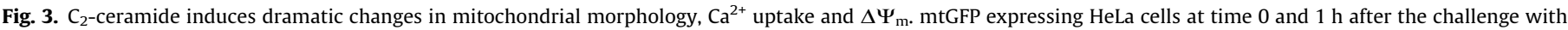

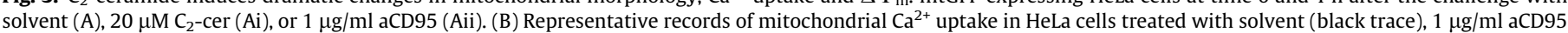

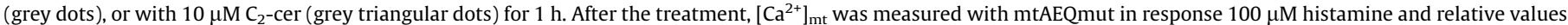

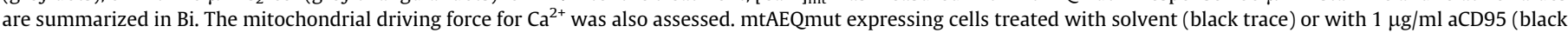

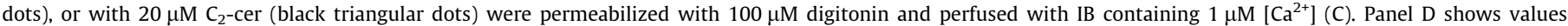
normalized to control of the $\Delta \Psi_{\mathrm{m}}$ measured with TMRM at time 0 and $1 \mathrm{~h}$ after treatment with the apoptotic stimuli.

\section{Discussion}

Apoptosis is a fundamental process involved in the regulation of organism development, tissue homeostasis, and defence against pathogens [29]. Deregulation of this process concurs to the onset of acute or chronic pathological states the most representative of which is probably neoplasia [30,31]. Apoptotic cell death is induced by a variety of stimuli that ultimately lead to the activation of a stereotyped series of intracellular events causing cell death and disassembling of the cell structures [32]. Nowadays, there is increasing interest in dissecting the intracellular pathways leading to cell death, trying to uncover metabolic differences in the apoptotic mechanism activated by diverse although equally effective stimuli. Interestingly, attention has been put on organelles such the endoplasmic reticulum, the Golgi apparatus and the mitochondria, as putative damage sensors and points of generation of local pro-apoptotic intracellular mediators [33]. Previously, it has been shown that short chain ceramide (e.g. $\mathrm{C}_{2}$-cer) induces $\mathrm{Ca}^{2+}$ release from the ER thus increasing $\left[\mathrm{Ca}^{2+}\right]_{\mathrm{c}}$ and $\left[\mathrm{Ca}^{2+}\right]_{\mathrm{m}}$, leading to cell death with a mechanism involving mitochondrial structural and functional alterations [27]. Noteworthy, the reduction of $\left[\mathrm{Ca}^{2+}\right]_{\mathrm{er}}$ as well as the buffering of cytoplasm $\mathrm{Ca}^{2+}$ changes [16], efficiently 
prevented mitochondrial damages and protected the cells from apoptosis [34]. Here, we show that $\mathrm{C}_{2}$-cer causes dramatic changes also on the ER morphology in parallel to a concomitant release of $\mathrm{Ca}^{2+}$ (Fig. 1B, D) that concurs to the degree of the damage.

Although we employed alternative strategies to counteract $\mathrm{C}_{2^{-}}$ cer induced modifications of the ER structure, none of them proved to be efficient except for the buffering of cytosolic $\mathrm{Ca}^{2+}$ level. Thus, both the inhibition of caspase activity by Z-VAD and the disassembly of the actin cytoskeleton by cytochalasin D did not impair the apoptotic effect of $\mathrm{C}_{2}$-cer. This indicated that modifications in the ER morphology were not depending on events downstream of apoptosis initiation but is likely linked to a triggering step almost concomitant with the lipid mediated toxicity.

Ceramide is well known for its ability to alter the permeability state of the mitochondrial outer membrane by promoting the formation of channels that render the organelles permeable to the pro-apoptotic factors such as cytochrome $c$ [35]. Although the level of permeability of the mitochondrial outer membrane correlates with the amount of ceramide present in the membrane [36,37], $\mathrm{Ca}^{2+}$ is known to be a critical sensitizing factor in the opening of the permeability transition pore (PTP), the molecular mechanism underlying the mitochondrial apoptotic transition [38]. Therefore, reduction or sequestering of free $\mathrm{Ca}^{2+}$ levels ameliorates $\mathrm{C}_{2}$-cer effect on the membranes. Our data suggest that morphological alterations occur also in the ER, and also this process is causally linked to alteration in cellular $\mathrm{Ca}^{2+}$ homeostasis, as the $\mathrm{C}_{2}$-cer mediated membrane damage is mitigated by chelating cytosolic $\mathrm{Ca}^{2+}$ with BAPTA (Fig. 2F). It can be envisioned that the gradual release of $\mathrm{Ca}^{2+}$ into the cytosol, and the activation of cytosolic effectors, impinge directly on the ER membrane already compromised by $\mathrm{C}_{2}$ cer thus provoking further release of $\mathrm{Ca}^{2+}$, establishing a vicious cycle that erodes the integrity of the whole structure.

Mitochondria, central players in the apoptotic process by integrating death signals through mitochondrial proteins belonging to the Bcl-2/Bax family $[2,30,39]$, are generally thought to remain intact and functional during the early events of apoptosis. The data presented here indicate that the signalling route operated by the lipid mediator $\mathrm{C}_{2}$-cer greatly modifies structure and function of mitochondria. Initiation of cells death by $\mathrm{C}_{2}$-cer induced a fast fragmentation of the mitochondrial network accompanied by dramatic changes of the organelle morphology and decreased capacity to accumulate $\mathrm{Ca}^{2+}$ released by the ER (Fig. 3B). This can be explained by two concomitant events. (1) In healthy cells the mitochondrial and ER networks have many sites of close contact, thus facilitating the transfer of the $\mathrm{Ca}^{2+}$ ions between the two compartments. (2) Alteration of the ER morphology and fragmentation of mitochondria could separate mitochondria from the ER network thus reducing the possibility of mitochondria to sequester ER-released $\mathrm{Ca}^{2+}$. Another not mutually exclusive hypothesis to explain the reduced $\mathrm{Ca}^{2+}$ uptake of mitochondria is linked to a direct damage of the organelle by $\mathrm{C}_{2}$-cer itself. This event is confirmed by experiments performed in permeabilized cells whereas $\left[\mathrm{Ca}^{2+}\right]$ of the extracellular/intracellular buffer is superimposed (Fig. 3C). In these experimental conditions mitochondria sense a $\mathrm{Ca}^{2+}$ concentration that is independent from the $\left[\mathrm{Ca}^{2+}\right]_{\mathrm{er}}$, giving the possibility to measure the real ion uptake capacity of the mitochondria. Yet, changes in mitochondrial membrane potential $\left(\Delta \Psi_{\mathrm{m}}\right)$ (Fig. 3D) suggest an intrinsic functional damage of the organelles independent of the ER. Interestingly, mitochondria of aCD95 stimulated cells show $\mathrm{Ca}^{2+}$ uptake capacity and $\Delta \Psi_{\mathrm{m}}$ (Fig. 3C, D) that resemble that of control cells, indicating that CD95 pathway causes cell death without interfering with mitochondrial physiology.

Altogether, these data demonstrate that organelles involved in intracellular $\mathrm{Ca}^{2+}$ homeostasis are differently affected in the cell death pathways controlled by $\mathrm{C}_{2}$-cer and aCD95 during apoptotic induction. Interestingly, mitochondria are completely unaffected, both morphologically and functionally, throughout the apoptotic route triggered by the engagement of the death receptor, whereas a major effect on $\mathrm{Ca}^{2+}$-mediated signalling, and activity of both organelles, is detected in the pathway operated by the lipid mediator, well before any biochemical or morphological sign of apoptosis. This notion implies radically different control mechanisms that can be explored, also pharmacologically, in further studies.

\section{Acknowledgments}

This work was supported by Telethon Grant GGP09128 (PP) and GGP06070 (FDV), AIRC (FDV, RR and PP), the Italian Ministry of Education, the Cariparo Foundation, the Italian Space Agency (ASI-OSMA) (FDV and RR), NIH (Grant \#1P01AG025532-01A1) to $\mathrm{RR}$, the Commission of European Communities (7th Framework Program HEALTH-F2-2007-202231) (FDV, RR), MYOAGE-Grant \#223576 to RR, Research Project Emilia-Romagna Region "Advanced Diagnostic Techniques" and "Moniter" (FDV). "Project of excellence” CARIPARO Foundation (RR, TP), MIUR PRIN and Strategic Project from the University of Padova to TP. BBSRC summer studentships scheme, Central Research Funds (Grant No. XAL44), RVC internal funds, Association "Il Circolo" to MC. UMDF, PRRIITT, FISM and University of Ferrara local funds to PP.

\section{Appendix A. Supplementary data}

Supplementary data associated with this article can be found, in the online version, at doi:10.1016/j.bbrc.2009.11.101.

\section{References}

[1] M.O. Hengartner, The biochemistry of apoptosis, Nature 407 (2000) 770-776.

[2] J.C. Reed, Apoptosis-regulating proteins as targets for drug discovery, Trends Mol. Med. 7 (2001) 314-319.

[3] D.W. Nicholson, Caspase structure, proteolytic substrates, and function during apoptotic cell death, Cell Death Differ. 6 (1999) 1028-1042.

[4] A. Strasser, L. O'Connor, V.M. Dixit, Apoptosis signaling, Annu. Rev. Biochem. 69 (2000) 217-245.

[5] K. Schulze-Osthoff, D. Ferrari, M. Los, S. Wesselborg, M.E. Peter, Apoptosis signaling by death receptors, Eur. J. Biochem. 254 (1998) 439-459.

[6] P.H. Krammer, CD95's deadly mission in the immune system, Nature 407 (2000) 789-795.

[7] T. Suda, A. Iwama, M. Hashiyama, S. Sakano, M. Ohno, Receptor tyrosine kinases involved in hematopoietic progenitor cells, Leukemia 11 (Suppl. 3) (1997) 451-453.

[8] P.T. Daniel, T. Wieder, I. Sturm, K. Schulze-Osthoff, The kiss of death: promises and failures of death receptors and ligands in cancer therapy, Leukemia 15 (2001) 1022-1032.

[9] R.G. Cutler, M.P. Mattson, Sphingomyelin and ceramide as regulators of development and lifespan, Mech. Ageing Dev. 122 (2001) 895-908.

[10] Y.A. Hannun, C. Luberto, Ceramide in the eukaryotic stress response, Trends Cell Biol. 10 (2000) 73-80.

[11] P.P. Ruvolo, Ceramide regulates cellular homeostasis via diverse stress signaling pathways, Leukemia 15 (2001) 1153-1160.

[12] G. Kroemer, N. Zamzami, S.A. Susin, Mitochondrial control of apoptosis Immunol. Today 18 (1997) 44-51.

[13] R. Rizzuto, T. Pozzan, Microdomains of intracellular $\mathrm{Ca}^{2+}$ : molecular determinants and functional consequences, Physiol. Rev. (2006) 369-408.

[14] M. Campanella, P. Pinton, R. Rizzuto, Mitochondrial $\mathrm{Ca}^{2+}$ homeostasis in health and disease, Biol. Res. 37 (2004) 653-660.

[15] C. Giorgi, A. Romagnoli, P. Pinton, R. Rizzuto, $\mathrm{Ca}^{2+}$ signaling, mitochondria and cell death, Curr. Mol. Med. 8 (2008) 119-130.

[16] P. Pinton, D. Ferrari, E. Rapizzi, V.F. Di, T. Pozzan, R. Rizzuto, The $\mathrm{Ca}^{2+}$ concentration of the endoplasmic reticulum is a key determinant of ceramideinduced apoptosis: significance for the molecular mechanism of Bcl-2 action, EMBO J. 20 (2001) 2690-2701.

[17] P. Pinton, C. Giorgi, R. Siviero, E. Zecchini, R. Rizzuto, Calcium and apoptosis: ER-mitochondria $\mathrm{Ca}^{2+}$ transfer in the control of apoptosis, Oncogene 27 (2008) 6407-6418.

[18] M. Campanella, G. Szabadkai, R. Rizzuto, Modulation of intracellular $\mathrm{Ca}^{2+}$ signalling in HeLa cells by the apoptotic cell death enhancer PK11195, Biochem. Pharmacol. 76 (2008) 1628-1636.

[19] N. Morishima, K. Nakanishi, H. Takenouchi, T. Shibata, Y. Yasuhiko, An endoplasmic reticulum stress-specific caspase cascade in apoptosis Cytochrome c-independent activation of caspase- 9 by caspase-12, J. Biol. Chem. 277 (2002) 34287-34294 
[20] R. Rizzuto, P. Pinton, W. Carrington, F.S. Fay, K.E. Fogarty, L.M. Lifshitz, R.A Tuft, T. Pozzan, Close contacts with the endoplasmic reticulum as determinants of mitochondrial $\mathrm{Ca}^{2+}$ responses, Science 280 (1998) 1763-1766.

[21] I. Kim, W. Xu, J.C. Reed, Cell death and endoplasmic reticulum stress: disease relevance and therapeutic opportunities, Nat. Rev. Drug Discov. 7 (2008) 1013-1030.

[22] M. Hoyer-Hansen, M. Jaattela, Connecting endoplasmic reticulum stress to autophagy by unfolded protein response and calcium, Cell Death Differ. 14 (2007) 1576-1582.

[23] P. Pinton, A. Rimessi, A. Romagnoli, A. Prandini, R. Rizzuto, Biosensors for the detection of calcium and pH, Methods Cell Biol. 80 (2007) 297-325.

[24] C. Scaffidi, I. Schmitz, J. Zha, S.J. Korsmeyer, P.H. Krammer, M.E. Peter, Differential modulation of apoptosis sensitivity in CD95 type I and type II cells, J. Biol. Chem. 274 (1999) 22532-22538.

[25] E. Rapizzi, P. Pinton, G. Szabadkai, M.R. Wieckowski, G. Vandecasteele, G. Baird, R.A. Tuft, K.E. Fogarty, R. Rizzuto, Recombinant expression of the voltagedependent anion channel enhances the transfer of $\mathrm{Ca}^{2+}$ microdomains to mitochondria, J. Cell Biol. 159 (2002) 613-624.

[26] R. Foyouzi-Youssefi, S. Arnaudeau, C. Borner, W.L. Kelley, J. Tschopp, D.P. Lew, N. Demaurex, K.H. Krause, Bcl-2 decreases the free $\mathrm{Ca}^{2+}$ concentration within the endoplasmic reticulum, Proc. Natl. Acad. Sci. USA 97 (2000) 5723-5728.

[27] P. Pinton, D. Ferrari, P. Magalhaes, K. Schulze-Osthoff, V.F. Di, T. Pozzan, R Rizzuto, Reduced loading of intracellular $\mathrm{Ca}(2+)$ stores and downregulation of capacitative $\mathrm{Ca}(2+)$ influx in Bcl-2-overexpressing cells, J. Cell Biol. 148 (2000) 857-862.

[28] M.R. Duchen, A. Surin, J. Jacobson, Imaging mitochondrial function in intact cells, Methods Enzymol. 361 (2003) 353-389.
[29] P. Nicotera, Development and death of neurons: sealed by a common fate? Cell Death Differ 9 (2002) 1277-1278.

[30] J.C. Martinou, D.R. Green, Breaking the mitochondrial barrier, Nat. Rev. Mol. Cell Biol. 2 (2001) 63-67.

[31] B. Zhivotovsky, G. Kroemer, Apoptosis and genomic instability, Nat. Rev. Mol. Cell Biol. 5 (2004) 752-762.

[32] A. Degterev, J. Yuan, Expansion and evolution of cell death programmes, Nat. Rev. Mol. Cell Biol. 9 (2008) 378-390.

[33] M.B. Ruiz-Arguello, G. Basanez, F.M. Goni, A. Alonso, Different effects of enzyme-generated ceramides and diacylglycerols in phospholipid membrane fusion and leakage, J. Biol. Chem. 271 (1996) 26616-26621.

[34] R. Foyouzi-Youssefi, S. Arnaudeau, C. Borner, W.L. Kelley, J. Tschopp, D.P. Lew, N. Demaurex, K.H. Krause, Bcl-2 decreases the free $\mathrm{Ca}^{2+}$ concentration within the endoplasmic reticulum, Proc. Natl. Acad. Sci. USA 97 (2000) 5723-5728.

[35] L.J. Siskind, R.N. Kolesnick, M. Colombini, Ceramide channels increase the permeability of the mitochondrial outer membrane to small proteins, J. Biol. Chem. 277 (2002) 26796-26803.

[36] L.J. Siskind, R.N. Kolesnick, M. Colombini, Ceramide forms channels in mitochondrial outer membranes at physiologically relevant concentrations, Mitochondrion 6 (2006) 118-125.

[37] J. Stiban, D. Fistere, M. Colombini, Dihydroceramide hinders ceramide channel formation: implications on apoptosis, Apoptosis 11 (2006) 773-780.

[38] P. Bernardi, L. Scorrano, R. Colonna, V. Petronilli, L.F. Di, Mitochondria and cell death. Mechanistic aspects and methodological issues, Eur. J. Biochem. 264 (1999) 687-701.

[39] P.T. Daniel, K. Schulze-Osthoff, C. Belka, D. Guner, Guardians of cell death: the Bcl-2 family proteins, Essays Biochem. 39 (2003) 73-88. 